This is a post-proof version of the manuscript published as McGowan, W. (2019) Performing Atrocity: Staging Experiences of Violence and Conflict. In R. Lippens and E. Murray (Eds.) Representing the Experience of War and Atrocity: Interdisciplinary Explorations in Visual Criminology. London: Palgrave Macmillan. 


\title{
Performing Atrocity: Staging Experiences of Violence and Conflict \\ Will McGowan
}

\begin{abstract}
In this chapter, I focus on the phenomenon of staged performance as a medium through which experiences of atrocity and violence are being increasingly articulated by those who experienced them directly. Drawing chiefly on the rationales underpinning Teya Sepinuck's Theatre of Witness and the collaborative work of Bravo 22 Company and The Drive Project, the chapter interrogates two broad questions emanating from projects of this nature. Firstly, for scholars exploring relationships between bodies, violence, injury, memory, memorialisation, and reconciliation, what exactly is it about these performances that should constitute 'the empirical'? Exploring a form of expression more apt, it may be claimed, at capturing the visual and the visceral, as well as the unspoken and the unspeakable, I argue that any analytical attempts to harness the power of staged performance must resist the temptation to reify its meaning. Rather than trying to decipher 'the real meaning' of a play, for example, I argue that only approaches which pay close attention to the practices of production and consumption associated with the performance are able to faithfully comment upon its all-important context. Secondly, I consider the potential ethical contradictions of documentary theatre as an artistic site of investigation for the social sciences which have frequently exemplified an overly individualistic and risk-averse logic characteristic of Western epistemology and pedagogy.
\end{abstract}

\section{Introduction}

This chapter focuses on the phenomenon of staged performance as a medium through which social actors directly affected by atrocity and violence articulate their experiences. Variously termed 'applied' (Prentki and Preston, 2009) or 'documentary' (Forsyth and Megson, 2009; 
Upton, 2011) theatre, the production of this artform often centres on the direct involvement of people who were present during a particular event or conflict. While documentary and filmmakers have often researched witnesses, survivors, and former perpetrators closely in an attempt to render their scripts, casting, and aesthetic arrangements more 'realistic', this commitment is taken a step further by prioritising their direct involvement as 'actors playing themselves'. Productions of this sort have been used to portray - or, rather, (re-)present conflicts in Northern Ireland, South Africa, former Yugoslavia, Lebanon, Palestine, Israel, Argentina, Peru, Sri Lanka, Uganda, and Australia (see Forsyth and Megson, 2009; Cohen, Varea, and Walker, 2011), among countless others. For scholars interested in the relationships between bodies, violence, injury, memory, memorialisation, testimony, and reconciliation, these artistic productions offer fascinating, and arguably unique, lenses through which to view their subject matters. Not all forms of 'applied' or 'documentary' theatre directly involve people 'acting out' their own stories but this variant of theatrical performance forms the focus of the chapter.

This form of participatory theatre raises a number of interesting and important epistemological, methodological, and ethical questions. In particular, I suggest that those turning toward these performances as an alternative and, as is frequently claimed, 'more realistic' way of understanding violent conflicts and their consequences must ask themselves a deceptively straightforward question. What exactly is it about these performances that should constitute 'the empirical'? Related, yet distinct, questions may also arise from this. What aspect of these performances should be considered 'authentic'? How 'faithful' can the depictions of historical events be through this artistic medium? What is to be considered 'truth'? How closely do the scripted narratives mirror those told originally and privately by the actors themselves? Notice, however, that each of these tributary questions implies a degree of trickery at play. The search for 'truth', 'authenticity', and 'faithful' depictions of reality each suggest a double bluff; 
that there is an account hidden in their somewhere, of greater or more valid epistemic value than others, just waiting for the diligent social scientist to reveal.

Rather than pursuing each of the above questions separately, they share some common enough characteristics, all inviting Garfinkel's (1975; emphasis added) salutary question: 'what's really happening?' As Garfinkel (1975) explains, a conventional approach to this question would encourage us to view real world action or events - in this case examples of documentary theatre - and subsequently construct a theoretical framework for explaining them. Using an appropriately constructed language, we would then be able to say something about the ontological reality of the performance and the actors within it; we would have a theoretical language with which to 'index' future examples of this phenomenon with varying degrees of approximation. Following Garfinkel, this approach is problematised and rejected in favour of one which places the questions, 'what is going on here?', 'what is really happening?', firmly within and a part of the context under study. Furthermore, in relation to documentary theatre productions, the very 'work' we do in asking 'what is going on here?' or 'what's really happening?' could itself be constitutive of what is really going on. ${ }^{1}$

The first two sections of the chapter focus on this issue, outlining the basic premise of documentary or applied theatre and offering a methodological critique of some of their main claims. These sections draw chiefly on the rationales underpinning Teya Sepinuck's Theatre of Witness and the collaborative work of Bravo 22 Company and The Drive Project. At no point in this chapter is the intrinsic value of documentary or applied theatre for those who derive pleasure, closure, or therapeutic benefits from it challenged. This point itself alludes to a paradox found within documentary theatre which is unpacked further. In the final section, I

\footnotetext{
${ }^{1}$ I am very grateful to Michael Mair at the University of Liverpool for many thought-provoking conversations, both on the specific topic being addressed here and, more broadly, on questions of epistemology and method. I must also acknowledge the advice and enthusiasm of Emma Murray in writing this chapter. The impetus for writing it actually originated in our discussions of a project at Liverpool John Moores University involving artists, academics, and men on licence within the criminal justice system which Emma both participated in and facilitated.
} 
consider the potential ethical contradictions of documentary theatre as an artistic site of investigation for the social sciences.

\section{Actors as 'actors': (re-)presenting experiences of violence and conflict}

Before focusing more closely on some of the epistemological assumptions implicated within existing analyses of applied or documentary theatre, it is useful to firstly outline and explain what is typically meant by it. The following explanation is a very broad conception of 'applied theatre', and although it hints at a number of issues which may be more or less relevant for this chapter, it is a helpful introduction for the uninitiated newcomer to this artform:

'Applied theatre' has emerged in recent years as a term describing a broad set of theatrical practices and creative processes that take participants and audiences beyond the scope of conventional, mainstream theatre into the realm of a theatre that is responsive to ordinary people and their stories, local settings and priorities. The work often, but not always, happens in informal spaces, in non-theatre venues in a variety of geographical and social settings: schools, day centres, the street, prisons, village halls, an estate or any other location that might be specific or relevant to the interests of a community. Applied theatre usually works in contexts where the work created and performed has a specific resonance with its participants and its audiences and often, to different degrees, involves them in it. Frequently those who engage in applied theatre are motivated by the belief that theatre experienced both as participant and as audience, might make some difference to the way in which people interact with each other and with the wider world. For both practitioners and participants there may often be an overt, political desire to use the process of theatre in the service of social and community change. For other practitioners and participants, the intention is less overt (but potentially no less political in its effect) and concerned with using theatre to draw attention to or reveal the hidden stories of a community. (Prentki and Preston, 2009: 9) 
As Prentki and Preston (2009) allude to above, applied theatre is perhaps best described by those engaged in producing it, since its disparate forms vary from each specific context to the next with notable differences in style, language, and purpose. Of special interest here are those variants of applied theatre which utilise the stories of victims and former perpetrators of particular conflicts. These stories are typically elicited by artistic directors and scriptwriters through one or several interviews, conversations, or meetings with such individuals and woven into a script which is then performed on stage by the very same individuals who provided their testimonies. In essence, (social) actors become (stage) actors playing themselves in front of an audience. This alone reveals the first notable feature of how such performances are produced and 'worked upon' in ways which are not always apparent in the finished production. Narratives and oral histories undergo differing degrees of curation and stylization, although in almost all cases extensive adaptation of individual's stories would not usually be advocated. Audiences are typically, though not always, constituted by the same community from which actors are recruited from. They often, though not always, participate at some point during performances, either through fluid interactions such as open-floor dialogue or dedicated question and answer-style discussion at the conclusion of the performance.

Two examples of this artform are Theatre of Witness and the collaborative work of Bravo 22 Company and The Drive Project. Both differ significantly in their practical approach but each places an emphasis on real stories told by those who experienced them first-hand. Teya Sepinuck is an Artistic Director, whose acclaimed Theatre of Witness, established in the United States in 1986 (Upton, 2011: 215), documents the stories of survivors, witnesses, former perpetrators, prisoners, refugees, and asylum seekers, among others, weaving together direct narratives in collaboration with scriptwriters and filmmakers. Upton suggests a parallel of assumptions between Theatre of Witness and the American experimental theatre of the 1960s 
and 1970s, assumptions which place special epistemic value on the 'pure presentation' of performers to audiences through self-expressive and authentic (non)acting rather than acutely conscious and even contrived role-playing (Upton, 2011: 215-16). Specific emphasis is placed upon testimony, supporting the notion alluded to above that the intention of the performance is partly to draw attention to hidden stories, or to give relatively little-known stories a greater audience than they otherwise would have. The website for the project describes its rationale as follows:

Theater of Witness is a form of testimonial performance and documentary films performed by people sharing their personal and collective stories of suffering, transformation and peace. Developed more than thirty years ago by Artistic Director Teya Sepinuck, the work brings people together across divides of difference to bear witness to each other's life experiences. Performers who have survived trauma, marginalization, oppression, and the complexity of the human experience, address some of society's most challenging issues from a multiplicity of perspectives. The performances weave the performers' stories together with music, spoken word, visual imagery and film into dynamic theater that humanizes the 'other' and cultivates compassion and empathy. The result is authentic, raw and powerful theater that celebrates the resilience of the human spirit. (Theater of Witness, 2018)

In addition to documenting the stories of the 'actors' involved, then, both Theatre of Witness and Bravo 22 share a commitment to the transformative potential of theatre for positive change for those involved. Bravo 22, for example, aims to use 'theatre as a vehicle for recovery', explaining that the "programme aims to give Service people and veterans new skills and experiences. It also hopes to improve confidence, self-awareness and motivation. All these support an individual's recovery and the transition into civilian life' (The Royal British Legion, 
2018). This is further iterated by Theatre of Witness with specific reference to 'story' as a genre and, importantly, an emotive means by which 'ordinary' people with 'extraordinary' experiences are able to cathartically generate individual and collective peace, empathy, and healing, satisfying the human need for recognition:

In these divided times, a story can warm hearts. A story can heal. A story can bring us together. Theater of Witness brings ordinary yet extraordinary people together, whose lived experiences inspire connection, healing and peace building. We all need to be inspired by stories of resilience, and transformation. Theater of Witness invites audiences to put a face and heart to complex societal issues, cultivates empathy, and celebrates the power of the human spirit to grow and transform. As one of Theater of Witness's dearest supporters and colleagues, Eamonn Deane from Derry Northern Ireland said: "Theatre of Witness is a modern phenomenon based on the oldest of needs - the need to tell our story, to be listened to, to find healing for ourselves and for everyone in our ability to empathize, to be generous and find light in the darkest pit.” (Theater of Witness, 2018)

While Theatre of Witness have staged a range of performances with actors from many different backgrounds, Bravo 22 has worked exclusively with physically wounded or psychologically traumatised service and ex-service military personnel. In a similar vein to other artforms of this kind, particular emphasis is placed on the fact that these stories come from real, as opposed to imagined or acting, soldiers. Perhaps what sets Bravo 22 apart to some extent is an explicit and a priori focus on the therapeutic utility of theatre rather than, primarily, its ability to reveal hidden or marginalised stories. While almost all forms of documentary theatre acknowledge a capacity for healing, sharing and promoting 'the resilience of the human spirit' (Theater of Witness, 2018), this forms a central aim of theatre for Bravo 22 which is said to promote both recovery and upskilling among its participants. It is important to bear in mind that each different 
project of this kind will have undergone differing and varying journeys to get to the point of production, including the funding of such projects, their intended participants and, crucially, their intended audiences. The balance between storytelling as carrying authentic weight for audiences and promoting positive ends for participants is not a mutually exclusive one but does tend to differ between projects. This relationship is explored later in the chapter. In almost all cases, the kind of strength, hope, recovery, or resilience being invoked is a recognition and celebration of existence, of life itself - of 'living and surviving to tell the tale' (ScheperHughes, 2008: 52). In this sense, resilience exhibits intrinsic and retroactive, rather than anticipatory or preparatory, qualities (see Schott, 2015).

There are two aspects of the above rationales that, I argue, should be interrogated a little more closely. Firstly, the claim that this form of theatre can 'reveal hidden stories' (Prentki and Preston, 2009: 9) should be subject to critical scrutiny. Part of the claim that theatre can reveal 'hidden', generally meaning previously unheard (at least publicly) or not widely shared, stories is that the 'actors' telling their stories are uniquely positioned to offer real and authentic accounts. This is only half true. As autonomous subjects, participants of this artform are no more or less capable of presenting themselves in more or less 'authentic' ways than in other contexts. Reality TV stands as a useful comparator here. Furthermore, far from being a 'complete account', the very contexts in which such performances are practiced should be considered equally important facets of the account itself. We are no closer to 'getting at' a more 'authentic', 'complete', or 'truthful' account of actors' experiences if we disregard this point as secondary.

The second aspect of this work, namely the acclaimed transformative potential of these performances, explicitly described in the Theatre of Witness rationale above, should also be examined in detail. During my PhD fieldwork I was fortunate enough to speak with several people who had participated in Theatre of Witness productions. Their enthusiasm and emotive 
recollections of being involved in the work confirmed many of the claims made by Theatre of Witness and other similar projects. However, where exactly are these transformations taking place? Where are they located and in what form? None of the participants that I spoke with emphasised the authenticity of the finished production or the unmasked truths that it managed to portray. Rather, they all described the actual process of taking part, speaking with Teya, meeting people they otherwise might not have spent time with, and interacting with audience members who had managed to track them down after years of separation or even between people who had never met but were present at the same historical event. In short, they enthused about the actual work-in-progress doing of the production and the intrinsic value of this for them. While this largely supports notions of strength, healing, and resilience outlined previously, it challenges a major premise that theatre require an audience at all or that the value of productions are only realised once performed on stage. These two related concerns are taken up in more detail in the following sections.

Interestingly, Ackroyd (2007) argues that 'applied theatre' in particular has gone from being the broad 'umbrella term' suggested in Prentki and Preston's description of it above, to a much purer and even exclusionary discourse which prioritises the utility of the artform, situating such utility firmly within a political frame (described by Ackroyd as 'evangelical'). Ackroyd's view that applied theatre appears to have been monopolised by a radical Marxist, Freirean pedagogy focused solely on its transformative political potential for certain groups, while shared by some (see O'Toole, 2007 cited in Ackroyd, 2007), is a moot point. ${ }^{2}$ Her

\footnotetext{
${ }^{2}$ The kind of theatre critically described by Ackroyd also closely resembles the work of Brazilian theatre director and theorist Augusto Boal, whose widely acclaimed Theatre of the Oppressed project (Boal, 1979) attempted, among other things, to bring Paulo Freire's (1970) tenets from Pedagogy of the Oppressed to life through participatory theatre. Ackroyd's political account of applied theatre is somewhat reductive, overlooking the frequently contradictory dynamics at play between the politically progressive aims of such projects and the popular ideas and practices of participants (see Snyder-Young, 2011). In short, while not all, or even most, theatre projects of this nature are designed a priori to promote political ends, the ones that are have no guarantees to success. Furthermore, within that body of projects whose aims are explicitly political, we can identify historical transitions between their approaches. Neelands (2007), for example, argues that far from reflecting the 'old left' politics of
} 
argument does, however, highlight an important practical issue. In addition to the contingent and often incidental impacts of these performances is a fundamental point about the generation of storied accounts. While they represent actual, already-taken-place-scenes in ordinary people's lives, they are produced against the above backdrop, emphasised explicitly by Theatre of Witness, complete with its transformative and even emancipatory promise. This is a predetermined outcome of the performance. Narratives are therefore necessarily mined for what Sacks (1995: 218) termed their 'storyable possibility', rather than for their ordinariness. Ordinariness and mundanity can still be highlighted on stage - as Sacks argues, we still recount extraordinary and even once-in-a-lifetime events within the parameters of ordinary conversational conventions. But the fact that applied theatre's primary and predetermined aims include reconciliation, including individual and collective transformation, perhaps suggests that spontaneous or natural presentation becomes fraught - more on this in the next section. This need not detract from the aesthetic or artistic quality, value, or impact of such performances, and certainly not their undeniable cathartic potential, but again brings into question totalising claims of 'truth' and 'authenticity'.

\section{Putting Testimony Centre Stage}

The broad notion of 'applied theatre' described above by Prentki and Preston (2009) is more specifically referred to as 'documentary theatre' by Upton (2011). For the purposes of this chapter, Upton's taxonomy of casting strategies offers a useful point of departure for thinking through the place of 'the empirical' within the forms of theatre described here. In particular,

redistribution which we might expect to see in the political caricatures offered by Ackroyd, contemporary applied theatre has moved discursively towards a 'new left' political position of recognition and difference. Even this claim confined to a Western context, we should surely bear in mind, may have expired since the global financial crisis of 2008-9, the wake of which has seen a resurgence in redistributive politics. The point again is that the politics of documentary and applied theatre are contingent accomplishments with little guarantee of fixity. 
her discussion of 'real people' as performers gets to the heart of a tension which arises for both relatively 'distant' intellectuals who may be interested in, but not invested in, the production of applied or documentary theatre and also for the artists very much embedded within that production process. For Upton (2011: 213, emphasis added), this tension hinges on the oxymoronic use of the phrase 'real stories' and other forms of marketing which rely on the word 'real' as a rhetorical device to juxtapose conventional theatre - 'with all that the word implies of art and artifice' - 'with the evidentiary force of the empirical'. Proponents of documentary theatre adopting such views of 'conventional' theatre, then, suggest (either implicitly or explicitly) that personal testimony and perpetrator or survivor narratives are themselves deemed to constitute the gold standard. Researchers falling into this trap, uncritically interpreting performers' personal accounts at face value, will find action exactly where they are told to find it - centre stage and in the spotlight.

Important as documentary and applied theatrical performances may be, we are likely to understand little of the processes involved in their often quite emotive manifestations if we ignore the production-in-process of such work. I use the word 'production' to refer to both the literal piece of work created at the end of an artistic process, but crucially also, methodologically, the contingent, unstable, and negotiated practices associated with that artistic process. 'Practice' and 'production' are preferable terms to 'construction' which, as Lynch (2011: 935) notes, implies a somewhat vague and relativistic notion of artifice rather than demonstrable action and performance (see also Hacking, 1999). Upton (2011: 216) elaborates on her earlier concerns, touched upon above, in great clarity with specific reference to Sepinuck's Theatre of Witness. At the heart of her critique lies a paradox between the billed authenticity of documentary theatre and the practical means by which it is rehearsed and delivered: 
[S]torytelling traditionally affords the teller ample opportunity to comment and reflect on, to embroider, challenge, distort and reinvent the story, thereby revealing the creative process at work in the making of the account. In the Theatre of Witness, that process seems strangely calcified by the time the stories reach the stage. A level of orchestrated intensity offers itself as unactorly and spontaneous emotional engagement: at times it occupies centre stage and seems to be the structuring principle of the performance. Ritualized or rehearsed, it is clear from the accompanying projections that the emotional register has been pitched in advance, as has the trajectory to a tearful public embrace in the final moments. The very markers of authenticity here reveal themselves to be constructed, and tension arises around the claims to honesty and truth in the whole enterprise.

Contrast this critical and sceptical deconstruction of the performed testimonies with the earlier promise often attributed to documentary theatre, with all of its 'evidentiary force of the empirical' (Upton, 2011: 213; emphasis added). Notwithstanding difficulties with the word 'construction' as emphasised above, there can be no better way of drawing attention to the misplacement of this promise than as Upton has here. As is clear from her account, the proclaimed 'natural', 'authentic', and 'spontaneous' potential of documentary theatre instead gives way to a hall of mirrors. At best, these include familiar constituents of theatre - ritual, rehearsal, and the careful pre-emption of emotional registers. At worst, they evince what is a pertinent metaphor, evocatively described as 'calcification' by Upton, for the social scientific analysis of documents and texts more broadly.

Focusing instead on backstage practice, documentary and applied theatre represents a prime opportunity for social scientists who are "rarely in a good position to explicate the technical activities in other fields, which often have their own methodologies and pedagogies' (Lynch, 2011: 933-34). Lynch's (2011) discussion centres chiefly on Science and Technology Studies (STS), along with the workplace practices of professional, skilled workers, whose 
common-sense activities often rely on highly technical, self-referential, and tacit exchanges between experts. This is hardly the case for, say, sociologists observing the practices of scriptwriters, directors, or actors, discussing the ways in which they might depict a particular scene, structure a particular musical sequence, or decide on lighting configurations during portrayals of violence such as gunfire or explosions. All of these require differing degrees of technical knowhow which may be beyond the immediate knowledge of the researcher, but they are not articulated in language totally unfamiliar to an ethnographer with little experience of stage productions, such as might be the case if we were observing nuclear physicists or mathematicians at work. ${ }^{3}$ Moreover, the ethnomethodological program pre-empts gaps in our own knowledge and provides clues for where best to look using a series of methodological devices with which to work from as primary starting points.

Drawing on literary theorist Kenneth Burke and his idea of 'perspective by incongruity', Garfinkel developed his own understanding of the way in which trouble could be used to prize open otherwise seemingly unproblematic and taken-for-granted scenarios and practices (Lynch, 2011: 932). He did so in the belief that while familiar and tacit understandings of everyday practice between actors may be difficult for outsiders such as researchers to identify, let alone fully grasp, we can more readily identify 'practical difficulty and discord [as opposed to implicit harmony] as leverage for revealing taken-for-granted practices that perform what a 'fact' or 'thing' is' (Lynch, 2011: 932). Thinking about our own particular skills, interests, hobbies, and other daily practices, which represent deeply familiar terrain, we too are most likely to become acutely aware of how what we are doing constitutes specific practice, honed in ways particular to us, only when challenged by practical obstacles. Such obstacles

\footnotetext{
${ }^{3}$ Whether verbal and conceptual understandings of practices under study will suffice, or whether researchers must also become competent in those practices before being able to adequately study and explain them remains a contested issue amongst ethnomethodologists (see Lynch, 2011: 934).
} 
might include direct challenges by others but are often much more minor events which need only slightly jar the usually harmonious humdrum of order. Attempts to impart knowledge of your familiar practices onto others, only to be met by confusion, disagreement, or resistance of varying degrees soon throws the particularity of your taken-for-granted perspective into sharp relief. These moments of 'trouble', or rupture of a scenarios' taken-for-grantedness, constitute important moments capable of revealing the contingency of practical accomplishments.

Some potentially illuminating sources of 'trouble' in this regard might be disagreements between actors, between actors and artists, in what has been left out or removed from people's original interviews or stories - what other sources of 'trouble' might there be that we would not be able to decipher in the finished production? What sources of controversy can be found in the very work-in-progress of the performance and how many of these 'make the final cut'? How far and how frequently do actors improvise? How much is that encouraged? Can we decipher instances where individuals go off-piste during performances or include material which they had previously agreed with the director they would leave out?

These kinds of questions represent the sort of unknown gems that film fans or traditional theatre enthusiasts love to find out more about. The more they know about their favourite actors or alternative plots previously unheard of the better. In this context, however, these questions become important for different reasons because of the kind of promised transformation constitutive of 'peace and reconciliation'. One good example of this is found in Teya Sepinuck's written account of her own projects (Sepinuck, 2013). One story she recalls involves a police officer in Northern Ireland meeting with a young man from a republican background. The young man's father had been shot and killed in an attack believed to be collusion between the police and the loyalist perpetrator. Sepinuck describes the first time the two men came together in the same room and the way the young man could look neither at the officer nor his old RUC uniform directly. For those present in the room, his body language and 
demeanour betrayed the obvious 'fears and prejudice' he carried toward the other man, whose very presence was emblematic of the perpetrators responsible for his father's death and the violation visited upon him and his family (Sepinuck, 2013: 183). Sepinuck goes on to explain how gradually things 'softened' between both men over the coming days (possibly weeks, we do not know the exact timescale from her account for certain) before opening night, to the extent that they even played a practical joke on her, convincing Sepinuck that the young man had been arrested just hours before the pair were due on stage. They had developed a positive relationship, becoming good friends and finding comfort in each other's common differences. Here we see how the production-in-process of the performance itself is constitutive of at least one of documentary theatre's aims; namely, its transformative, reconciliatory, and therapeutic potential. Can this process be faithfully reproduced on stage? Indeed, is it even possible to present and re-present this process to audiences retrospectively? As though the 'real' reconciliation were happening before their very eyes?

Whether we view this transformation as complete or in-process matters both politically and for the acclaimed transformative resonance of such performances. Where complete, uncontroversial, or 'old' examples of these reconciliatory transformations between victims and former perpetrators, or between former perpetrators and security service personnel, are presented as though they were still 'live' and in flux, we may expect to see the kind of 'calcified' process critically described by Upton (2011:216) earlier. As Reinelt (2009: 7) points out, the promise of this artform is rooted within a realist epistemology, while its experience for actors, audiences, and artists cannot be anything other than a 'phenomenological engagement'. Consequently, its promise lies 'not in the object [performance] but in the relationship between the object, its mediators (artists, historians, authors) and its audiences'.

The rise of documentary and applied theatre for depicting the experiences of victims and former perpetrators loosely parallels a wider concern with prioritising victim testimony 
within the social sciences. Whether taking interviews, focus groups, or video data as our focus, or indeed the more 'radical' potential of documentary and applied theatre, it is important not to overstate the epistemological power or ontological authenticity testimony affords us. In all cases, if we defend a view steadfastly which deems testimony and narrative itself to be constitutive of where the 'real' action lies, how deeply are we really interrogating our research practices, how faithfully are we reflecting on them, and how far are we prepared to admit and report the contradictions and fallibilities inherent in our work?

\section{On (More) Faithful Representation}

Two key ethical issues arise when thinking through the practical accomplishment of documentary theatre and our attempts to research it. Firstly, there may be very different expectations of what constitutes 'good ethical practice' between social scientists and artists. While the former may advocate for, or at least be bound by an expectation of, participant anonymity, the latter often places great value on rendering the true identity of participants transparent and public, with full autonomy and ownership of people's stories remaining with them. ${ }^{4}$ This is an important issue and one which can only be worked out on an individual, caseby-case basis between collaborators on the same project. It presents many of the archetypal hurdles of interdisciplinary collaboration, including the practical negotiation of unfamiliar research norms and differences between safeguarding protocols. There are also likely to be marked differences in the emphases placed on documentary theatre's role for its participants. While social science research ethics committees will be quick to flag up the risk of participation for 'actors', artists and some therapists speak of documentary theatre's cathartic and even

\footnotetext{
${ }^{4}$ Other considerations include not only anonymity but also the potential costs of re-enactment for actors. Jeffers' (2008) fascinating article about participatory theatre practice with refugee groups illustrates this tension particularly starkly, explaining that asylum seeker and refugee actors are necessarily embroiled in the production of 'victim narratives' because of the appalling processes underpinning the UK government's asylum system driven by the precedent to validate stories of suffering.
} 
emancipatory potential. Disagreements or differences in style are thus likely to fall into three subcategories: participant anonymity versus public knowledge, individual intellectual property versus collective 'ownership', and the risk of participation versus a belief in positive emotional outcomes for participants and the acquisition of new skills and experiences.

There is arguably a tendency toward deficit thinking in the social sciences when it comes to ethics, which often overlook the positive potential that performances such as this can bring to those involved. Insurance, litigation, and risk - this is the stuff of contemporary Western social science ethics (see Haggerty, 2004 for a critical discussion of this 'ethics creep'). Of course, there is good reason to pre-empt and carefully consider risk when it comes to participant wellbeing and it is not my intention to suggest otherwise here. However, the 'procedural' ethics (Guillemin and Gillam, 2004) of university review boards, whose task is to forecast problematic issues before they arise, rather than equip researchers to deal with live issues as and when they arise, are arguably poorly placed to predict the impact of applied theatre on its participants. The fact that people are typically taking part in such performances in spite of the researcher's project or study means the aspect of the research requiring ethical clearance would be the observational and ethnographic work, rather than decisions about the individual actors' involvement (unless, of course, the researcher were also an actor/participant). In many ways, this would likely mitigate some of the usual concerns which ethical review boards may have around, for instance, interviewing participants about sensitive topics.

A second question, intimately connected to the above discussion about what aspect of documentary theatre should necessarily constitute 'data' or the empirical, arises in relation to the interpretation of our data and thinking reflexively about doing so. Following Lynch (2000), reflexivity is not understood here to be epistemologically 'virtuous' or 'emancipatory', but rather ubiquitous and unremarkable. It describes 'a property of 'accounts' (verbal expressions, signifiers, texts and other formal devices) that is furnished by taken-for-granted usage' (Lynch, 
2000: 34). Summarising an ethnomethodological conception of reflexivity, Lynch's following words offer a useful point of departure and return for thinking about how we should best interpret documentary theatre, doing ethical justice to 'what really happened':

\begin{abstract}
'[Reflexivity] is ubiquitous and 'uninteresting', but, as Garfinkel demonstrated in his studies of the 'documentary method of interpretation', the reflexive relationship between accounts and accountable states of affairs can become vicious (and thus 'interesting') when analysts attempt to treat decontextualized documents, signs and indicators as self-sufficient accounts of 'what really happened' or 'what was really meant'. It can become vicious because the conditions for making sense of a document are not 'contained' in it; they are reflexive to the circumstances of use.' (Lynch, 2000: 34)
\end{abstract}

Again, reality TV raises some interesting parallels in this regard. It is not that people's behaviour or reactions on reality TV are in fact more 'real' (often the opposite seems true) and that we should take them at face value, but rather that the way people behave and interact in an unnatural and staged environment which is being sold to us as 'real' provides a sociologically interesting medium through which to view society's attitudes. In particular, the ways people choose to present themselves in reality TV situations are themselves specific to the production of the show in question, yet often also raise interesting (meta)questions about cultural tastes and social values.

Another example of a 'decontextualized document', taken at face value and treated as 'self-sufficient', is a finished theatrical production in which the stories, emotions, and intentions of the actors involved are treated as 'contained' within the final performed body of that work. Contrast this with the messy and contingent practice of the work itself, inclusive of the actions and interactions during the production of the work alluded to above, prior to its public unveiling in finished form (Goffman's (1959) reference to the 'backstage' carrying here 
both metaphorical and literal significance). Importantly, the actions of actors, artistic directors, and social scientists undertaking a study of the former, should all be understood to be rendering these accounts 'accountable' and 'intelligible' (Lynch, 2000: 42). This rendering would include aspects of our research which we might not typically acknowledge or deliberately make visible in somewhat more 'virtuous' attempts to analyse our data reflexively. Examples of this include the recruitment of participants by artistic directors, undocumented conversations between researchers and directors about their productions, the presence of researchers who might be observing rehearsals and early attempts to conceptualise theatrical performances, and conversations that might be had between researchers and actors behind the scenes. Such insights give researchers a supposedly fuller account of the performance's context and the actors' personal, private, and non-scripted life history which may or may not become apparent during the performance. In an analysis of 'the play', for example, as a finished production (or document) to be interpreted upon completion, all of these facets of the research process simply become necessary, but not directly relevant, 'backgrounds' and 'contexts' (Lynch, 2000: 42), without which we could not 'get to the task' of beginning a proper analysis. If we wish to proceed with inquiries into documentary theatre as a significant and interesting visual and cultural phenomenon, as I believe we should and it is, then it is imperative that we avoid falling into this trap.

In addition to the considerations outlined above around participant anonymity versus public knowledge, individual intellectual property versus collective 'ownership', and the risk of participation versus a belief in documentary theatre's transformative, cathartic, and even emancipatory potential, an analytical approach which parallels Lynch's (2000) notion of 'reflexive accountability' would encourage us to think more carefully and holistically about documentary theatre's substance and form. In short, 'the theme of reflexive accountability implicates a novel domain of sociological investigation: the 'uninteresting' local achievement 
of (ordinarily and professionally) accountable social order (and disorder)', rendering that which occurs 'backstage' as viable and 'researchable' phenomena' (Lynch, 2000: 43; emphasis in original). Applying this principle to documentary and applied theatre, we can usefully sort these phenomena into what Hughes, Kidd and McNamara (2011: 207) term 'practice as research' and 'research into practice'. The former represents what has been subject to scrutiny throughout this chapter for offering only a flat, two-dimensional interpretation of the performance which can 'always only indicate a temporarily abstracted fragment of the practice'. However, as they rightly caution, when we delve deeper into the working mechanisms driving the performance ['research into practice'] we still only 'hold the practice still for a moment so that we can look at its parts. But we make a mistake if we assume that those parts added together come to the sum of the whole' (Hughes, Kidd and McNamara, 2011: 207).

\section{Conclusion}

The phenomenon of staged performance as a medium through which experiences of atrocity and violence are articulated is both an evocative and pertinent form of representation for anyone engaging with theatrical artforms and the visual, sensory, and performative expression they facilitate. Drawing on the rationales underpinning Teya Sepinuck's Theatre of Witness and the collaborative work of Bravo 22 Company and The Drive Project as indicative examples, this chapter has interrogated two broad questions emanating from projects of this nature. Firstly, for scholars exploring the affective, sensory, and existential relationships between bodies, violence, injury, memory, memorialisation, and reconciliation, what exactly is it about these performances that should constitute 'the empirical'? Exploring a form of expression more apt, it may be claimed, at capturing the visual and the visceral, as well as the unspoken and the unspeakable, I have argued that any analytical attempts to harness the power of staged performance must resist the temptation to reify its meaning. Rather than trying to 
decipher 'the real meaning' of a play, for example, only approaches which pay close attention to the practices of production and consumption associated with the performance as centrally important phenomena are able to faithfully comment upon its all-important context. Rather than discrediting or disregarding the power of documentary and applied theatre, as some critics might, I argue, along with others (inter alia Fisher, 2005; Hughes, Kidd and McNamara, 2011; Utpon, 2011), that we should invest our research time into such performances but pay closer attention to the specific and unfolding form such production practices take. The 'doing' of these performances is where the 'action' is, sociologically speaking, and not in their varied success at conveying 'what really happened', historically and pedagogically speaking. Such performances should not be taken as ontological moulds of the 'actors' involved, but rather as practical, and therefore contingent, accomplishments which are themselves constitutive of the things they are attempting to convey. Rather than reading such performances as texts capable of telling us 'what really happened' or 'what was really meant' within their scripts in a didactic sense, we must recognise that their true meaning is to be found in their particular and situated 'circumstances of use' (Lynch, 2000: 34).

Secondly, I considered the ethical implications such projects may have for the social sciences, including sociology and criminology, which have typically exemplified overly individualistic and risk-averse logics so often characteristic of Western epistemology and pedagogy. This extends beyond considerations of harm, safety, and wellbeing to questions of value. While social science is perhaps more likely to find instrumental value in theatrical presentations of war, conflict, and atrocity, for what they tell us about past events and experiences, the artists typically involved in their creation place equal weight on the intrinsic value of the performance for those participating in it and their audiences in the present. In many respects, dichotomies such as this oversimplify the working practices at the heart of this chapter. Social scientific and artistic projects are hardly mutually exclusive pursuits and many 
such projects will dovetail naturally, but there is no escaping the sharp distinctions typically found across disciplinary and pedagogical boundaries. Professionals working either side of these boundaries may sometimes struggle to understand or appreciate the other's logic, but these discussions should be encouraged toward further collaboration and subject to situated studies of working practice. Recent developments in 'methodography', that is, the empirical study of research methods in practice and of the working rationales of professional researchers (Greiffenhagen, Mair and Sharrock, 2011; 2015) provide one such avenue for understanding more about the relationship between social scientists and artistic directors.

One somewhat silent party in this discussion has been the audience. Their participation in these performances, and the incidental conversations and interactions that occur during and after them between audience members and between audience members and stage actors, are again prime focal points (for an indicative example of this, specifically relating to Sepinuck's recent work in Northern Ireland, see Grant and Jennings 2013: 317). Some spectators may be emotionally captivated by the individuals on stage and their personal stories, others more by the overall moral and political messages conveyed by the performance as a collective. We must of course remember that as researchers we too are spectators. Even by focusing on backstage practices or frontstage omissions, we should never feel contented or comfortable enough to declare that we know how any two performances are accomplished hypothetically. If we do, we risk becoming Garfinkel's (1975) magician, holding sole power over the ability to explain how the 'trick' was done. We would give an account of how 'authentic' experiences are conveyed on stage based on select performances with no recourse for others to see exactly how those performances came to be constituted as such and not otherwise within, or from, our accounts. Just as the magician leaves the audience with a 'virtual production account of the trick', so too would we only be able to offer a version of what such productions conveyed based on their intended aims and concomitant successes or failures at 
achieving them. The trouble is, whether we are talking about stage productions or interview transcripts, 'you can't consult that production version of the trick and get anywhere close to how the trick indeed was done' (Garfinkel, 1975). Regardless of whether 'actors', accounts are, or are not, 'more authentic', and no matter how 'calcified' (Upton, 2011: 216) or doctored their performed testimonies may appear to us, the ontological power to voluntarily bear witness and to share their stories lies with them, providing many with immense benefits. The burden to decipher such accounts lies not with 'actors', whose depictions may or may not mirror the historical record or the experiences of their contemporaries, but with those of us who choose to ask what might be 'really happening' (Garfinkel, 1975). 


\section{References}

Ackroyd, J. (2007) Applied Theatre: An Exclusionary Discourse. Applied Theatre Researcher 8(1): $1-11$.

Boal, A. (1979) Theatre of the Oppressed. New York: Theatre Communications Group.

Cohen, C.E., Varea, R.G. and Walker, P.O. (Eds.) (2011) Acting Together I: Performance and the Creative Transformation of Conflict. Oakland: New Village Press.

Fisher, A.S. (2005) Developing an ethics of practice in applied theatre: Badiou and fidelity to the truth of the event. Research in Drama Education 10(2): 247-252.

Forsyth, A. and Megson, C. (Eds.). (2009). Get Real: Documentary Theatre Past and Present. Basingstoke: Palgrave Macmillan.

Freire, P. (1970) Pedagogy of the Oppressed. New York: Continuum.

Garfinkel, H. (1975) The Boston Seminars, Seminar 5. Available at: http://emcalegacy.info/garfinkel.html [Accessed 03/08/2018].

Goffman, E. (1959) The Presentation of Self in Everyday Life. New York: Anchor.

Grant, D. and Jennings, M. (2013) Processing the Peace: An Interview with Teya Sepinuck. Contemporary Theatre Review 23(3): 314-322.

Greiffenhagen, C., Mair, M. and Sharrock, W. (2011) From Methodology to Methodography: A Study of Qualitative and Quantitative Reasoning in Practice. Methodological Innovations Online 6(3): 93-107.

Greiffenhagen, C., Mair, M. and Sharrock, W. (2015) Methodological Troubles as Problems and Phenomena: Ethnomethodology and the Question of 'Method' in the Social Sciences. British Journal of Sociology 66(3): 460-485.

Guillemin, M. and Gillam, L. (2004) Ethics, Reflexivity, and "Ethically Important Moments" in Research. Qualitative Inquiry 10(2): 261-280.

Hacking, I. (1999) The Social Construction of What? Cambridge: Harvard University Press.

Haggerty, K.D. (2004) Ethics Creep: Governing Social Science Research in the Name of Ethics. Qualitative Sociology 27(4): 391-414.

Hughes, J., Kidd, J. and McNamara, C. (2011) The Usefulness of Mess: Artistry, Improvisation and Decomposition in the Practice of Research in Applied Theatre. In B. Kershaw and H. Nicholson (Eds.) Research Methods in Theatre and Performance. Edinburgh: Edinburgh University Press.

Jeffers, A. (2008). Dirty truth: personal narrative, victimhood and participatory theatre work with people seeking asylum. Research in Drama Education, 13(2), 217-221.

Lynch, M. (2000) Against Reflexivity as an Academic Virtue and Source of Privileged Knowledge. Theory, Culture \& Society 17(3): 26-54. 
Lynch, M. (2011) Harold Garfinkel (29 October 1917 - 21 April 2011): A remembrance and reminder. Social Studies of Science 41(6): 927-942.

Neelands, J. (2007) Taming the political: the struggle over recognition in the politics of applied theatre. Research in Drama Education 12(3): 305-317.

Prentki, T. and Preston, S. (Eds.) (2009) The Applied Theatre Reader. London: Routledge.

Reinelt, J. (2009) The Promise of Documentary. In A. Forsyth and C. Megson (Eds.) Get Real: Documentary Theatre Past and Present. London: Palgrave Macmillan.

Sacks, H. (1995) Lectures on Conversation, Volumes 1 and 2, G. Jefferson (Ed.), With an Introduction by Emanuel A. Schegloff. Oxford: Blackwell.

Scheper-Hughes, N. (2008) A Talent for Life: Reflections on Human Vulnerability and Resilience. Ethnos 73(1): 25-56.

Schott, R.M. (2015) 'Not Just Victims...But': Toward a Critical Theory of the Victim. In H. Marway and H. Widdows (Eds.) Women and Violence: The Agency of Victims and Perpetrators. Basingstoke: Palgrave Macmillan. pp.178-194.

Sepinuck, T. (2013) Theatre of Witness: Finding the Medicine in Stories of Suffering, Transformation, and Peace. London: Jessica Kingsley Publishers.

Snyder-Young, D. (2011) Rehearsals for revolution? Theatre of the Oppressed, dominant discourses, and democratic tensions. Research in Drama Education: The Journal of Applied Theatre and Performance 16(1): 29-45.

The Royal British Legion (2018) Bravo 22 Company: Recovery and Wellbeing through the Arts. [online] Available at: https://www.britishlegion.org.uk/getsupport/recovery/bravo-22-company-recovery-and-wellbeing-through-the-arts/ [Accessed 03/08/2018].

Theater of Witness (2018) About Theater of Witness. Theater of Witness.org [online] Available at: http://www.theaterofwitness.org/about/\#about-what [Accessed 03/08/2018].

Upton, CA. (2011) Real people as actors - Actors as real people. Studies in Theatre \& Performance 31(2): 209-222. 